\title{
YOUTH AND THEIR TRAINING NEEDS
}

\author{
Abdullah Nialim Baginda \\ Assistant Director, Ministry of Culture, Youth and Sports \\ Malaysia
}

The views expressed in this paper are those of the author and do not necessarily reflect those of the Government of Malaysia

The nation's interest in youth

Youth accounts for a large share of the world's population. It is now estimated that in the four decades between 1960 and the year 2000 the 15-24 age-group will increase from 519 to 1,128 million. Today more than $75 \%$ of this age-group live in developing countries - 59 million in Africa, 322 million in Asia and 44 million in Latin America.

The first inescapable fact is that government interest and action relating to youth work haveincreased greatly in almost all countries in the last few years. This has happened irrespective of ideologies or political systems, and for reasons which are many and well-known. The most important of these reasons may well be a combination of demography, as suggested by the above figures, the expansion of educational opportunity and the increased effectiveness of mass media for communication. This is neither the time nor the place to elaborate on the population problem; suffice it to remark that it has not, of course, affected all countries, nor is its impact the same on those which are affected by it.

The impact of increasing educational opportunities

In the developing countries, such as those in the Asia/ Pacific region, great emphasis is being placed on education, both formal and informal, and a sizeable portion of the national budget is spent on education. Educational upportunity has increased for most young people, even though not everywhere has it kept pace with the increasing population. For the richer countries, this has meant the possibility of secondary education for all and higher 
education for rising proportions of those who complete secondary education. In terms of percentage of the total world population, however, the figures are still comparatively small. For the majority of children increased educational opportunity has meant the possibility of perhaps six years of primary schooling. Paradoxically, this leads to increased frustration. Not only do they face the situation that what is possible for some is not possible for all who would like to continue their formal education; more disturbingly, the education received, however long or short its duration, raises expectations for the future which, either because of the insufficiency of its quantity or of its quality or of both, cannot be fulfilled. This situation is worsened by the spread of information, through the printed word and by the various media of audio-visual communication. Opportunities not only exist: they are known to exist. So, too, is the fact that only a few have access to such opportunity, and that it is denied to many.

Educationally and socially, therefore, the increased provision of services, facilities and opportunities of all kinds which are now accepted as basic rights has led to an insatiable demand for more. That such a demand at present cannot be met may be intrinsic to the nature of difficult processes of development. It is worth noting that owing, perhaps, to the spread of information, among other reasons, the key to youth problems seems to have changed in the last few years from the need to stir and rouse people from ignorance or apathy, and to create a demand for education or activity, to that of the difficulty of meeting the demand for education, for action, and for direct participation by youth at all levels.

If we are to accept that education is no longer a time in life but rather a dimension of life, the nation ought to grant each individual adequate education, guaranteeing him a certain number of years of training, with a first unit at the beginning of his life and the remainder to be spread out through the rest of it, according to his needs and aspirations. It is obvious that such a concept would necessarily involve a basic reform of the whole educational system and, particularly, the establishment of democratic structures to make it possible for everyone to be informed and to participate, as well as to achieve critical behaviour. This will enable them to become free, conscious and responsible human beings.

Social factors affecting youth

Rapid industrialisation and urbanisation are effecting vital changes in our social structure. The family unit, for example, is 
slowly weakening and appears incapable of providing effective and acceptable guidance to the young. In developing countries, the generation gap may be further complicated by the fact that the parents of today were brought up in a way quite unknown and irrelevant to their children as they prepare for the world of tomorrow.

Human society is in constant evolution, economically, technically and socially: what was rare yesterday is taken for granted today and this is particularly true of information, communications and contacts. Young people avail themselves of these new facilities faster than adults. Their sense of solidarity, their thinking and their decision-making are affected by it and seem to differ in many ways from those of their elders. The effort of education is therefore not only to be made by young people but al so by adults, who will safeguard what is valuable in their tradition only if they know how to communicate it, how to share it, and how to co-operate with the young in adapting it to the needs of today and tomorrow.

Permanent education of this sort involves long-range prospects for the future and consists essentially of reciprocal and permanent relationships among sectors hitherto dissociated: youth and adults, in school, out of school and at work, educational action without leadership (mass media) and with leadership, the educators and the educated, etc.

Formal education can equip the young with the technical skills necessary to absorb them into industries, but these skills will be insufficient in themselves. They must be supplemented with some forms of organised activities where youth can organise themselves and participate in group work in order to promote a sense of belonging and identifying with others, and to provide an opportunity for self-expression and the development of a sense of social discipline, civic consciousness and responsibility to self and the society.

Youth work and youth programmes

This group-approach youth work, therefore, is to provide young people with an opportunity to discover and develop their personal resources of body, mind and spirit, so that they will be better equipped to live as mature, creative and responsible members of a democratic society. Through youth work young people can be helped to develop themselves and take an active role in nation building. Developing countries in this region are undergoing rapid industralisation and social revolution and the aim is primarily to 
provide a better living standard for our people. In this attempt, our young people must shoulder a greater part of the responsibility. They must not only identify themselves with the efforts of progress but must also take an active part in national development programmes. Given proper guidance, leadership and motivation, youth will undertake this task in the proper spirit.

It is obvious, of course, that the need for developing leadership among and for youth in the Asian and Pacific regions is enormous, reflecting the size and significance of the youth population itself. If we classify youth as the group between 15 and 24 years of age, then this group makes up approximately $20 \%$ of the population of the region, i.e. around 322 million in all. This group, made up as it is of those who are completing school, who have recently left school or who have just come into the employment market, is clearly of the highest importance from the view-point of human resources development. We may also note that, both absolutely and proportionately, it is the major focus of unemployment and under-employment in the region, particularly of unemployment in urban areas, where the proportion of youth in the total population is highest. Reports on the region indicate two areas in which the planned development of Asian countries has proved rather deficient, namely employment promotion and the qualitative improvement of education. Not only are there too few jobs for the rapidly increasing population, but formal education at all levels seems in many ways dysfunctional to the needs of developing economies; these deficiencies affect youth most of all.

Serious short-comings in the fields of education and employment are among the factors which have brought youth to the fore in the major political scene in many Asian countries, though to a lesser extent in the Pacific area. In recent years, young people in these countries have played an increasingly important role in challenges to establish institutions and patterns of social behaviour, and in a few instances have been instrumental even in the overthrow of governments. The latter consideration, undoubtedly, is the key to the belated interest which governments are beginning to show towards the youth problems.

A growing range of programmes and measures aimed at youth are now appearing in countries of the region as an outcome of the pressures and processes that have been suggested above. Initial emphasis seems to have been placed upon programmes of education and training, including vocational training, for the very large groups of out-of-school youth, school drop-outs, and early school leavers. These have been followed by a variety of other 
programmes seeking to involve young people in national development efforts. In addition, increased attention is being given to programmes which seek either to develop youth leadership or to provide adult cadres with special skills in dealing with the social problems of youth.

As many of the above-mentioned measures are of recent origin, it is difficult to make an assessment of their achievements at this stage and information on them is rather scarce. However, a generalised prognosis may be attempted. In the economic sphere, radical policy departures are called for in order to generate employment on a massive scale and to appreciably reduce inequities of income and wealth in favour of the low income majority. In the closely-related political sphere, no less fundamental policy initiatives are required to broaden the base of public participation in national life and to democratise social structures.

The leadership of youth

In group situations, youth leaders are normally elected by their peers or contemporaries; a great majority of them serve as volunteers, especially when they act as leaders with small groups or local branches. Only a few youth leaders, however, are professionals and most of these work as organisers or administrators at regional, national or even international level. In practice, it is often difficult to draw an exact dividing line between adult and peer youth leaders, either by age or in respect of their role of leader, as seen either by themselves or their members. Increasingly, the ranks of professional adult leaders are being filled by those who have "graduated" as peer leaders. In many cases they have made the transition without any kind of formal training, either because no opportunities of training existed or because it is accepted that their practical experience is an adequate or more than adequate substitute for formal training.

However, until the number of young people involved in youth work grows considerably larger than at present and thus provides a sufficient base from which future adult leaders may be drawn, it is likely that a proportion of the youth leaders will have to be recruited and trained for the first time later in life. In any case, even though young people who have been in youth groups provide a sufficient number of recruits for leadership, it may still be useful to have a certain proportion of "outsiders" brought in at the adult leader ship level, both to avoid "in-breeding" and the complacency and self-centredness to which it can give rise, and to strengthen the communication between the community at large and the youth sector within it. 
The role of the youth leader is to teach, advise, befriend and generally assist young people on the basis of his knowledge, skill, experience and maturity, which will normally be greater than theirs. The function of a youth leader may be discharged in a wide variety of environments - educational, social, technical, industrial, agricultural, etc. It is usual to distinguish between the actual dedicative role of the school teacher or educator and the work of a youth leader.

His role in relationship to youth is dependent on ties of family kinship. In various societies it appears that one or both parents traditionally carried out, on a formal or informal basis, certain duties of instruction, advice and assistance. In periods of rapid social change, especially of change due to modernisation and the application of technology, many of these functions are no longer discharged within the kinship net-work. It can be argued that it is this default which has given rise to the need for the adult youth leader. This same process of the overtaking of traditional methods of instruction has been recognised in the realm of formal instruction in the basic necessities of a modern society. These affect vocational skills and requirements for survival involving food, shelter and the money economy, etc., and have been comparatively swiftly incorporated into a community structure in the form of an organised school system. Only gradually, however, has the need to provide similarly for the informal, out-of-school needs of young people been recognised.

The need for a training policy

In order to meet the increasing demand for youth leaders a training policy should be evolved, which could very well be a consistent part of a national youth policy, whether this be a policy of the government or of a non-governmental organisation. If it is a non-governmental organisation, the training and general policy for youth will have to be consistent both with governmental policy and with the principles and ideology of the organisation itself; they will also be closely related, with suitable modifications to suit local cultural conditions, to the international policy of the non-governmental organisation, if such exists. Problems may arise when the objectives of the government and of the voluntary organisation appear to be irreconcilable.

The training of youth leaders should be conceived and practised as a continuing and progressive process, involving the development of the individual personality of the trainee as well as the imparting of specific knowledge, understanding and skill. In 
this sense, training is an unending process.

Responsibility for the training policy should be carried by the Ministry, council or organisation which has responsibility for national youth policy as a whole. The Minister or other senior governmental person responsible will find it useful to have an advisory body of specialists to make proposals about training policies and programmes. This body should be fully representative of the various forms of governmental and non-governmental youth work and also of allied educational and social fields.

The carrying out of training programmes should, wherever possible, be done on a decentralised basis, utilising local resources of government and non-governmental bodies wherever appropriate. It will usually be necessary to establish a system of financial subsidies for training programmes with funds from central government sources.

Most developing countries suffer shortages of middle and higher level manpower and a lack of facilities through which to train this manpower. Priorities will have to be established within the comprehensive planning of human and material resources as to which kind of employment and training should be encouraged. Youth leadership, therefore, finds itself in competition with a number of other professions. For it has only comparatively recently emerged as a profession, even in the highly industrialised countries, and there still appears some uncertainty about the content and method of training for it as well as its validity as a separate discipline or occupation. It is therefore likely to fare badly in comparison with the better established and recognised professions in education, health and social welfare. Nevertheless a strong case can be argued for giving youth leadership high priority in the present demographic, economic and social situation of most developing countries. But an adequate training policy cannot be expected unless certain prior decisions of policy have been taken which allocate priority to youth work as a whole.

It is therefore of the highest importance to secure a training staff of the highest calibre, dedicated and versatile enough to remain in touch with the realities of the young world. This might involve the provision of facilities to enable these workers and leaders to interchange between teaching or theoretical work and practical field posts, travelling domestically and abroad in order to make comparative studies of problems and techniques.

A national policy for training should prepare leaders and workers who can meet the needs of all young people,but there 
should be special provision for training for work with different groups of youth, namely, those already involved in an organised fashion, those who are interested and the often forgotten masses. A comprehensive training policy should provide support for professional youth workers, for youth leaders working up through the ranks of youth organisations and for leaders emerging through spontaneous youth movements. Since the spontaneous youth leaders are sometimes considered suspect and difficult to manage, measures should be taken to maintain a dialogue with them and to protect them from being unduly harassed by the established groups. A national youth policy should set priorities as to the groups of youth for whom trained leaders are needed. Student groups usually produce their own leaders. The largest masses of youth live in rural areas. Their needs are often the most acute and merit priority, even though it may be easier to carry out work with urban youth because of the resources and the attraction of urban living for the youth worker. In some situations, rural youth drifting to the cities may prove to be the group most urgently needing training for leadership. Policies should make provision for attracting trained people to such work. Priorities should also be established by types of training and indeed several countries emphasise the training of trainers whose work can have the greatest multiplier effect.

In countries where no single governmental service is responsible for youth work, where various governmental Ninistries and services encourage the training of youth workers, steps may have to be taken to define and locate a central body on which responsibility for policy and co-ordination is placed. Some measures for the co-ordination of effort are advisable; for example, responsibilities may be delegated to a special youth service, or a co-ordinating body such as a National Youth Board may be organised to plan and direct training.

The magnitude of the task is so great that governments must accept a role in promoting training; where government youth organisations are strong they may be expected to initiate training. In some countries it is considered desirable for governments to leave most of the initiative to non-governmental organisations and to support their work with financial assistance, advisory services, material aid and facilities, but not to interfere with their basic educational work except by way of assuring high standards of training. Government assistance should be provided on a regular and impartial basis according to criteria and conditions which are publicly established in advance. 
In any event, in order that the best use may be made of scarce resources, there should be close co-ordination between the government youth services and non-governmental organisations for the development of a training policy. This co-ordination may take place through a governmental organisation with a representation from non-governmental bodies or by having representatives of the public authorities on a co-ordinating body of nongovernmental organisations.

It is important that all youth organisations, including the political youth organisations, should join in the discussion on policy for training, even though the widely divergent political youth groups may wish to persuade youth organisations which have no political affiliation to adopt a particular line of thinking. Their presence is needed, since they often have a serious contribution to make to development. Their view-points often sharpen the youth need for questioning society and the experience may be valuable in the training of politicians who are sympathetic to the need for a comprehensive national youth policy.

A national policy for the training of youth leaders should not be an abstract formulation of what would be ideal for a country but should be based on the recognition that young people have an essential role to play in the development of the nation and on the realistic assessment of the resources likely to be available in the light of that recognition.

The professional youth worker

For both volunteer and professional workers there should be a deliberate policy of providing suitable incentives and rewards. For volunteers this will involve ensuring that they do not suffer hardship, material or otherwise, as a consequence of their voluntary service, and the provision of regular occasions and different means by which the government, and the community at large, can publicly express its gratitude and appreciation for the services rendered. For professional youth workers, it is necessary to provide financial remuneration, conditions of work, a career structure and professional status at least equal to or comparable with those in other professions with similar qualifications and levels of training.

Encouragement should be given to all professional youth workers to improve their capacity and efficiency by providing study leave, by generally improving their status and by establishing good public relations and a code of ethics, through professional associations of youth workers and allied professions. Care should 
be taken to ensure that those professionally engaged do not become socially and culturally isolated, either because their work is exceptionally demanding or because as adults they are in danger of becoming separated from their contemporaries due to their attempt to identify with youth.

It may be useful to plan and organise youth worker training with certain special emphases. These might be administrative, counselling, organisation and direction of programmes, instruction in skills, etc. Some degree of specialisation should arise as the number of youth workers, both professional and volunteers, increases. However, most youth leaders will need to have a basic competence in all areas. A basic understanding of the determinants of behaviour, of the ways in which it can be influenced and the ways it changes at various stages of individual development will be required by all youth workers irrespective of the particular aspect to which they devote most attention. It is also probable that more understanding of and skill in administrative tasks will be required by those who reach the more senior positions.

If the academic status of youth workers is to be recognised there will have to be an increase in the number of courses in well-established institutions: universities and extra-mural departments, schools of social work, teacher training institutions, youth leader training colleges and community development training centres. It is known that a number of governments are setting up national training centres or training institutes for the advanced training of workers. In spite of the danger that these centres may offer too rigid a programme, they are generally considered worthwhile because they can fill the gaps in the training offered by institutions in the formal education system. They are important for the continuity of experimentation and progressive training experience. As residential centres, they contribute to a sense of national solidarity among the youth leaders of a nation, and for government personnel they can promote a trend away from specialised training towards polyvalent training, e.g. a sports leader can learn techniques of encouraging action in community development. In offering their facilities to non-governmental organisations, national training centres can encourage training in line with national priorities.

A national policy for the training of youth workers can no longer escape having some international perspective. Government officials, national youth council members and leaders of nongovernmental organisations should have an overall view of the assistance available from various international agencies. They should develop a policy for the most strategic use of such 
assistance and co-operation. While the value of assistance from external sources is recognised, it should be handled judiciously in order that it may be related to the needs and circumstances of the receiving countries. Imported assistance in training should not be conditional on the importation of foreign ideas which may be incompatible with local conditions.

It is known that in many countries where the whole approach to training has been imported a thorough-going reappraisal may become necessary after the gaining of political independence and the establishment of new priorities for social and economic development. Policy makers may not find it necessary to reject imported training simply because it is imported. In retaining forms of training used by other countries they may have the opportunity to compare their own experience elsewhere.

Mutual aid in training

Bilateral and multi-lateral assistance should be directed in large measure to the establishment and strengthening of local training institutions and programmes. The feasibility of collaboration by various international agencies in the establishment of multi-disciplinary regional training centres with special provision for youth training should be explored. The Commonwealth, being an international body, is considered appropriate to promote the setting up of such an establishment.

A number of people from abroad are being utilised as trainers. These include both experts and volunteers, many of whom are 30 years of age. In some countries their knowledge, technical skills, modern equipment and materials are accepted as positive elements in a society in rapid transition. Elsewhere there is a fear that they may be irrelevant because of the difficulties of the cross-cultural transmission of content and method. These experts and volunteers should be selected for their knowledge, understanding and respect of local cultures and circumstances, and for the particular function they will be required to carry out. It is important that their contribution correspond to real needs and that their methods be in line with indigenous thinking.

The training of youth in the local situation is essential to cater for national needs. However, it has long been felt that training beyond national borders is particularly necessary now that the concerns of so many youths around the world are similar and the issues affecting youth in one area so quickly arouse interest and influence the actions of youth in many others. These trends affect the work of the professional and voluntary leaders. But in 
view of the fact that many youth leaders are unable on their own, or even with local support, to travel abroad for this purpose, there is a need for some form of organisation to provide travel facilities and scholarships for short-term visits or long-term professional training abroad. There is still a deep-felt need for experts, lecturers and highly competent trainers who can contribute to worldwide or regional training meetings dealing with youth education, organisational management, adolescent and youth psychology, sociology of youth, community development and human relations.

Training for unemployed youth

Unemployment among young people is one of the most critical problems facing the developing countries. While in the long run it can only be improved by the expansion of employment opportunities for all workers, a number of special measures can be taken to counter the problem of youth unemployment. This is a question which is receiving increasing attention. Unemployment and under-employment in developing countries affect all children and young people. One particular problem is that of educated unemployment among boys and girls who have completed secondary or higher education. A certain distaste for agricultural and other manual work in preference to office work, especially in government service, has led large numbers of young people to pursue studies preparing them for over-crowded occupations, though at the same time the demand for technical and scientific workers cannot be met. Some studies have been carried out by the International Labour Organisation and it was found, among other things, that, although extensive measures were being taken to develop technical and vocational training in certain countries, these countries still had difficulty in training enough highly skilled workers to carry out the many industrial projects undertaken under their development plans. The problem of unemployment in most developing countries has become increasingly prominent.

Generally speaking, research into special youth mobilisation schemes has shown the importance of the problems involved in the vocational guidance and training of young people, in utilising them as fully as possible for national economic and social growth, and in developing special programmes directed towards preparing young people for work and work opportunities.

Although vocational guidance has long been practised in most industrialised countries, it is only in its earliest stages in the developing countries. Only very recently have services been built up to help young people to choose an occupation and to find employment. The principles laid down in the Vocational Guidance 
Recommendations of 1949 underline International Labour Organisation activities in this field. However, there is a clear need for research aimed at evolving methods and techniques better adapted to the special conditions of the developing countries. It is understood that the International Labour Organisation provides technical assistance to countries wishing to establish improved vocational guidance for youth employment services. In recent years there has been a considerable increase in the number of countries receiving expert assistance in the field of aptitude testing and other selection techniques, especially for the selection of trainees for the larger vocational training schemes. There has also been some increase in the assistance provided for youth employment service organisations.

National Youth Service as a training device

In order to meet critical problems, particularly in regard to the anomaly represented by large numbers of untrained, unemployed young people on the one hand and the acute need for economic development on the other, several developing countries have evolved a new form of training programme, popularly known as "National Youth Service". Such a programme is essentially catering for two distinct functions, i.e. the provision of training and the productive employment of unskilled unemployed youth. Some countries also have programmes which instil the community service concept among the educated youth.

A great majority of current programmes come under the first category, i.e. programmes for "disadvantaged" youth. Various criteria are being employed so as to provide as wide a distribution of facilities to as many young people desiring such training as possible. In most cases there has been no need to enforce any obligation, as most programmes attract more volunteers than there are openings available. However, in a small number of countries legislation instituting civic service is being enforced and this includes certain provisions making participation obligatory for certain age-groups and other categories of young people. This type of civic service is increasingly being accepted as fulfilling a national (as distinct from strict military) service obligation.

The training and work content of this programme varies according to the age, sex, individual needs and educational qualifications of participants, and the country's needs and financial resources. The proportion of actual training and work placement is determined by the choice between putting the emphasis on longterm consequences or on activities with short-term results. 
Training is normally adapted to national needs and should be related to existing or future employment opportunities. Throughout the programme, productive work is aimed at social and economic development.

Any form of education and training increases the expectation of the individual for better living, although primarily it is considered merely a vehicle leading to such a goal. Trained youth must be syphoned out, either to be employed by some agencies or engaged in some form of occupation, in order to give way to new entrants. One of the objectives of training is to make young people self-reliant, independent and resourceful. However, the establishment of such a programme being a political and economic move, the authorities may have to embark on intensive programmes of constantly generating employment, which can be very restrictive particularly in a country with limited potential and slow economic growth. It is therefore essential to study the nation's resources and potential before resorting to this type of training programme.

Settlement schemes as an extension of training

A proportion of the graduates of the National Youth Service are inevitably channelled to settlement schemes where they embark on agricultural activities. In this way, relatively rapid growth of less developed areas can be achieved. For the nation, apart from the economic potential, a small part of the unemployment problem is being solved. For participating youth, the hope for better living rises with the progress they make in respect of their new venture.

Settlement schemes for youth came into being as a means of providing employment and hence a livelihood for the sons of farmers who, due to shortage of land, are unable to eke out a decent living on existing land. These schemes are seen as an extension of training in agricultural management and communal existence. Some of these schemes are sponsored by government agencies while others are organised entirely on a voluntary basis, with perhaps a small amount of subsidy from government sources. In the former case, taking Malaysian experience as an example, the responsible agencies make the necessary preparation of the land before the young settlers enter, whereas in the latter instance the youth work on the land right from the beginning and take part in all the processes, including the construction of their own rugged accommodation. The difference in the two types of settlement is evident and there is undoubtedly a greater amount of administrative procedure that needs to be observed in the former case. Both 
require strict discipline and a clear-cut hierarchy of leaders and responsibilities.

While such settlement schemes are creditable, a number of sociological problems are inevitable. Most schemes, for obvious reasons, are located away from administrative centres and, indeed, even away from villages or communities. However, the pressure for a decent living drives a great many young people to take part in these schemes, despite all the hardships and self-denials that are imposed on them, by either the organisers or the environment itself. Critics are reluctant to support these schemes because of the social and psychological implications of such an existence.

The participants have to live in an artificial environment, as the community is mostly made up of young men of about the same age, without women, children or adults. Coming as they do from all parts of the country each participant brings his own set of norms and code of behaviour and therefore it is essential that a common standard exists. The period of social adjustment can be made more painful by the rigid discipline being enforced simultaneously throughout the whole life in the settlement. Living in very close quarters with people of about the same age over a period of time can be very irritating and such a situation may cause a great strain on the individuals. Despite all these drawbacks, the dropout rate, as far as Malaysia is concerned, is negligible.

Settlement schemes for unemployed youth still have great political appeal, although the performance of the majority of such schemes has been of uneven quality. The sociological problems resulting from "youth only" schemes are becoming more evident. Selection of the youths is a critical factor. There is a need to relate existing agricultural education to settlement schemes. Fortunately greater emphasis is now being given to schemes in which youth are actively involved in all stages of their development, in order to minimise the sociological problems and the very heavy capital and operating costs of traditional settlement schemes. Despite some new promising approaches, settlement schemes still remain very costly and will therefore probably continue to play a limited role in any government 's programmes for youth involvement.

Youth participation

The one common factor in the general unrest among students and young people in developed countries is the demand 
for participation. This demand and a desire to conduct their own organisations is also appearing in the previously adult-governed youth movements. It seems quite certain that youth organisations for post-school adolescents will certainly have to ensure full participation of members, not only in programming, but also in all kinds of decision-making.

Recruitment for youth leadership can be seen as starting from within the youth groups themselves, through promotion and election of officers, etc. The recruitment and selection of trainees is directly related to and dependent on the motivation for providing the training in the first instance and the specific post of position and type of leadership which the trainee will undertake. Like training itself, selection should be a continuous and progressive process. To insist on selection in the form of educational, psychological or other forms of tests may not be realistic when the supply of leaders, as is most frequently the case, is considerably below the demand. However, some minimum requirements can and should be normally maintained.

The great shortage of youth leaders and youth workers gives rise to the need for a policy to promote the rapid development of training. There appears to be a difference of opinion as to the concept which governs the formulation of such a policy. A view has been expressed that research into the existing requirement estimates of expected need for the next 10-30 years should be undertaken and that planning techniques should be utilised in devising an overall policy. However, some organisations prefer a more simple and flexible approach so that their resources may be rapidly mobilised to most emergency needs. Hence, the training policy should have both long range goals and short term objectives. In countries where a national youth policy already exists, the national training policy should be consistent with it, or a high level decision should be taken to give priority to the twining of youth leaders so that the standard of youth work may be raised and the youth policy carried out more effectively. In countries where decisions on national priorities have not given rise to a governmental youth policy or to a national planning office for youth affairs, there should be a great measure of harmony between the national policy for the training of youth workers and those elements relating especially to youth within more general governmental policies for political emancipation, through the development of resources, universal education, etc. Their training to this end could add dynamism to governmental programmes and provide evidence to youth that co-operation to meet the needs of society need not mean acceptance of any particular partisan political outlook on development. 
The United Nations Report on Long-Term Policies and Programmes for Youth in National Development states that:

\footnotetext{
"in very broad terms, a difference should be made between the bulk of young people in the developed and developing areas of the world. They are united in their liberal ideas, interest in music and the arts, their quest for education, aspiration for peace, human right and social justice, but certain distinctions are imposed by their respective economic situations and traditions."
}

The Report declared that:

"In relation to youth, the action by the $\mathrm{UN}$ family would have three broad objectives:

(a) to facilitate the contribution of young people to development and to ensure that their efforts are directed to feasible ends which are a relevant and integral part of the total development plan;

(b) to strengthen the motivation of young people to participate in and contribute to programmes of self-help and mutual assistance;

(c) to protect young people from exploitation and excessive participation in development activities which might harm their health or hinder their physical or mental growth and their development as individuals and as citizens."

Youth in developing areas should therefore become the agents and beneficiaries of development rather than its victims.

As already mentioned, young people in the developed world demand participation. In Africa, Asia and Latin America, however, there is already considerable participation by youth in public affairs. The United Nations Report states:

"The demand for more education now should not be allowed to obscure the great strides in education which have been taken in these countries over a relatively short period, which have 
emphasised the educational differences between the older and younger generations. They have allowed all these younger people, able to read, write and understand political issues, to participate in a way seldom open to their parents. It has made them the agents of their families in outside affairs. As a result, it has been the younger generation which has generally been active politically and the younger generation which has often provided support for political movements."

It cannot be said that in the developing countries young people feel a lack of participation. The reverse is often true and young people in developing countries often direct and control political affairs. On the other hand, not all young people share in this participation and these countries have young populations with high expectations. The political leaders, therefore, must be attentive to the feelings of young people.

Participation by itself is not the only consideration in the examination of the future of youth work in developing countries. In many developing areas the development of resources that have either remained untouched for many years or been exploited for the benefit of colonial masters is a slow process, involving the accumulation of capital for investment and monumental increase in productivity. While the value of participation in terms of the individual 's sense of involvement in the national destiny is undoubted, it should be recognised that not all programmes will meet with instant or complete success. The young people must be advised that the fruition of their labour may not be realised this year or next, but that they must be satisfied that they are contributing to some measure of progress towards personal and national goals.

The role of women and girls

Throughout this paper, there has been no special mention of the role of young women and girls. This is a deliberate omission in view of the fact that women's liberation movements are springing up everywhere; no doubt young women in developing countries will also rise and demand complete emancipation. They may well gain their victory, with equality in respect of privileges and also responsibilities. For this reason, what has been referred to earlier in this paper should be applicable to both young men and women. 
Conclusion

The primary goal of youth work is the social education of young people. Such a definition is not unimportant since the aim changes as society changes. Developing countries are much concerned with basic education, economic needs and helping young people to create their place in a changing society: it is their critical involvement in their community which is the goal. We often hear statements of the aims of youth work, as for example, "to offer young people in their leisure time opportunities of various kinds, complementary to those of home, formal education and work, to discover and develop their personal resources of body, mind and spirit and thus the better to equip themselves to live the life of mature, creative and responsible members of a free society". This definition has not spent its force but it needs to be given fresh interpretation and emphasis in the light of contemporary society. It could be taken to mean that youth work takes place in special organisations, special places and at particular times, "complementary to home,formal education and work." Youth work should be seen to be present in many places, being concerned with relationships between generations and between young people and their community; it can take many forms and lead to different types of provision, of which organisations and centres are only examples. In the broadest terms, therefore, youth work is the response by informal methods to the personal, educational and social needs of the young in relation to society. 